\title{
Biophysical Characterization of the Interaction of Endotoxins with Hemoglobins
}

Jörg Howe ${ }^{1}$, Malte Hammer ${ }^{1}$, Christian Alexander ${ }^{1}$, Manfred Rössle ${ }^{2}$, Karin Fournier ${ }^{3}$, JeanPierre Mach ${ }^{3}$, Thierry Waelli ${ }^{4}$, Reginald M. Gorczynski ${ }^{5}$, Artur J. Ulmer ${ }^{1}$, Ulrich Zähringer ${ }^{1}$, Ernst Th. Rietschel ${ }^{1}$, Klaus Brandenburg ${ }^{1}$

${ }^{1}$ Forschungszentrum Borstel, Leibniz-Zentrum für Medizin und Biowissenschaften, Borstel, Germany

${ }^{2}$ European Molecular Biology Laboratory, Hamburg, Germany

${ }^{3}$ Institute de Biochemie, Université de Lausanne, Lausanne, Switzerland

${ }^{4}$ Clinique La Prairie, Montreux, Switzerland

${ }^{5}$ Dep. of Surgery and Immunology, University Health Network, Toronto, Canada 


\begin{abstract}
Bacterial endotoxin (lipopolysaccharide, LPS) is the major component of the outer leaflet of the outer membrane in Gram-negative bacteria. During severe infections, bacteria may reach the blood circuit of humans, and endotoxins may be released from the bacteria due to cell division or cell death. In particular enterobacterial forms of LPS represent extremely strong activator molecules of the human immune system causing a rapid induction of cytokine production in monocytes and macrophages. Various mammalian blood proteins have been documented to display LPS binding activities mediating normally decreasing effects in the biological activity of LPS. In more recent studies, the essential systemic oxygen transportation protein hemoglobin $(\mathrm{Hb})$ has been shown to amplify LPS-induced cytokine production on immune cells. The mechanism responsible for this effect is poorly understood. Here, we characterize the interaction of hemoglobin with LPS by using biophysical methods. The data presented, revealing the changes of the type and size of supramolecular aggregates of LPS in the presence of $\mathrm{Hb}$, allow a better understanding of the hemoglobin-induced increase in bioactivity of LPS.
\end{abstract}




\section{Introduction}

Bacterial endotoxin (lipopolysaccharide, LPS), with its hydrophobic membrane anchor lipid A constitutes the major lipid component of the outer membrane of Gram-negative bacteria. In mammals LPS exhibits high biological activity, which may be beneficial at lower but pathophysiological at higher concentrations, due to excessive cytokine production by cells of the immune system [1]. Chemically, LPS consists of a sugar portion with varying lengths of oligo- or polysaccharide chains depending on the type of bacterial strain, i.e., rough (R)-type LPS of the Re- to Ra-chemotypes expressed by mutant enterobacterial strains or smooth (S) form LPS of wild-type enterobacteria. Even within a single bacterial strain a considerable degree of chemical microheterogeneity is commonly found within the oligo- or polysaccharide portion of LPS. The polysaccharide component is covalently linked to the hydrophobic anchor of LPS, lipid A. The latter is known to represent the 'endotoxic principle' of LPS, since it is the minimal chemical structure which elicits the endotoxin-typical activities [2]. Various endotoxin-binding proteins such as lactoferrin and high-density lipoprotein (HDL) are known to bind to LPS (lipid A) thereby decreasing the bioactivity of LPS [3, 4]. Hemoglobin $(\mathrm{Hb})$, the four subunit globular oxygen-carrying protein of vertebrates and some invertebrates, represents an important systemic LPS-binding protein. $\mathrm{Hb}$ is present in the cytoplasm of red blood cells. In addition, lower concentrations of cell-free Hb are constantly released into the circulation due to an inherent intravascular hemolytic disruption of erythrocytes which can be largely increased during the course of severe anemic hemoglobinopathies such as sickle cell disease [5, 6]. Previously it was shown that the interaction of Hb with LPS results in a significant increase of the biological activity of LPS [7-9]. The mechanism of this augmenting effect, however, remained elusive. In first experiments, we characterized the interaction of $\mathrm{Hb}$ with enterobacterial LPS and lipid A, and found that the increase of the LPS-induced cytokine induction was due to an enhanced adoption of the 'endotoxic conformation’ of the lipid A component of LPS [10]. Thus, we 
found, that cross-linked $\mathrm{Hb}$ is able to convert an inactive pentaacylated having a lamellar conformation lipid A into an endotoxically active cubic conformation [11]. There is evidence that the enhancement of the biological activity is also associated with a Hb-induced disaggregation of LPS $[11,12]$.

Here, a biophysical analysis of the interaction of Hb with enterobacterial LPS is described. The investigations were done with highly purified reagents, i.e., with Hb from fetal sheep and rough mutant LPS from Salmonella minnesota, in some cases also its hydrophobic moiety lipid A, to exclude any influence of unknown contaminants. Our data show that on interacting with $\mathrm{Hb}$, the type and size of LPS supramolecular aggregates are changing.

\section{Material and Methods}

\section{Lipopolysaccharide}

Lipopolysaccharide from Salmonella enterica rough mutants Re and Ra ( S. minnesota R595 and R60, respectively) were extracted by the phenol/chloroform/petrol ether method [13] from bacteria grown at $37^{\circ} \mathrm{C}$, purified, and lyophilized. Free lipid A was isolated by acetate buffer treatment of LPS Re. After isolation, the resulting free lipid A was purified and converted to its triethylamine salt [4]. Results of all the standard assays performed on the purified LPS and lipid A (analysis of the amount of glucosamine, total and organic phosphate, and the distribution of the fatty acid residues, with chemical methods and mass spectroscopy) were in good agreement with the chemical composition known for LPS R595 and R60.

\section{Hemoglobin}

The preparation of $\mathrm{Hb}$ from ovine fetal blood was done as described earlier [14]. 


\section{Cytokine assay}

For an examination of the cytokine-inducing capacity of the endotoxin:Hb mixtures, human mononuclear cells (MNC) were stimulated with solutions of endotoxin and $\mathrm{Hb}$ and the TNF $\alpha$ production of the cells was then determined in the supernatant. MNC were isolated from heparinized (20 IU/ml) blood taken from healthy donors and processed directly by mixing with an equal volume of Hank's balanced solution and centrifugation on a Ficoll density gradient for $40 \mathrm{~min}\left(21^{\circ} \mathrm{C}, 500 \mathrm{~g}\right)$. The interphase layer of MNC was collected and washed twice in Hank's medium and then once in serum-free RPMI 1640 which contained 2 mM Lglutamine, $100 \mathrm{U} / \mathrm{ml}$ penicillin, and $100 \mu \mathrm{g} / \mathrm{ml}$ streptomycin. The cells were resuspended in serum-free medium and the cell number was equilibrated at $5 \times 10^{6} / \mathrm{ml}$. For stimulation, 200

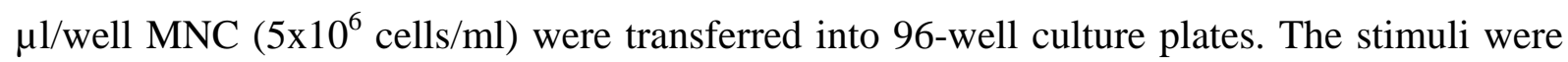
serially diluted in serum-free RPMI 1640 and added to the cultures at $20 \mu l$ per well. The cultures were then incubated for $4 \mathrm{~h}$ at $37{ }^{\circ} \mathrm{C}$ under $5 \% \mathrm{CO}_{2}$. Supernatants were collected after centrifugation of the culture plates for $10 \mathrm{~min}$ at $400 \mathrm{~g}$ and stored at $-20{ }^{\circ} \mathrm{C}$ until determination of cytokine content.

Immunological determination of TNF $\alpha$ in the cell supernatant was performed in a sandwichELISA as described elsewhere [15]. 96-well plates (Greiner, Solingen, Germany) were coated with a monoclonal antibody against TNF (clone 6b from Intex AG, Muttant, Switzerland). Cell culture supernatants and the standard (recombinant TNF [rTNF], Intex) were diluted with buffer. After exposure to appropriately diluted test samples or serial dilutions of standard rTNF, the plates were exposed to rabbit anti-human TNF $\alpha$ Ig-peroxidase conjugate. The plates then were shaken $16 \mathrm{~h}$ at $4{ }^{\circ} \mathrm{C}$ and subsequently washed 6 times in distilled water to remove the free antibodies. Subsequently, the colorimetric reaction was started by addition of tetramethylbenzidine $/ \mathrm{H}_{2} \mathrm{O}_{2}$ in alcoholic solution and stopped after 5 to 15 min by addition of $1 \mathrm{~N}$ sulfuric acid. In the colorimetric reaction, the substrate is cleaved enzymatically, and the product was measured photometrically on an ELISA reader (Rainbow, Tecan, Crailsham, 
Germany) at a wavelength of $450 \mathrm{~nm}$; the values were related to the standard. TNF $\alpha$ was determined in duplicate at two different dilutions and the values were averaged.

\section{Fourier-transform infrared spectroscopy (FTIR)}

The infrared spectroscopic measurements were performed on an IFS-55 spectrometer (Bruker, Karlsruhe, Germany). The lipid samples were placed in a $\mathrm{CaF}_{2}$ cuvette with a $12.5 \mu \mathrm{m}$ teflon spacer. Temperature-scans were performed automatically between 10 and $70{ }^{\circ} \mathrm{C}$ with a heating-rate of $0.6{ }^{\circ} \mathrm{C} / \mathrm{min}$. Every $3{ }^{\circ} \mathrm{C}, 50$ interferograms were accumulated, apodized, Fourier-transformed, and converted to absorbance spectra. For strong absorption bands, the band parameters (peak position, band width, and intensity) were evaluated from the original spectra, if necessary after subtraction of the strong water bands.

The main vibrational bands used for the analysis are the symmetrical stretching vibration of the methylene groups $v_{\mathrm{s}}\left(\mathrm{CH}_{2}\right)$ located around $2850 \mathrm{~cm}^{-1}$, a measure of order of the lipid A chains [16], and the amide I mode, predominantly $\mathrm{C}=\mathrm{O}$ stretching, located in the wavenumber range 1700 to $1600 \mathrm{~cm}^{-1}$, with a band component pattern characteristic for the type of secondary structures [17].

\section{Isothermal Titration Calorimetry (ITC)}

Microcalorimetric measurements of protein binding to endotoxins were performed on a MCS isothermal titration calorimeter (Microcal Inc.), Northampton, MA, USA) at $37^{\circ} \mathrm{C}$. Endotoxin samples $(0.1 \mathrm{mM})$ were dispensed into the microcalorimetric cell (volume $1.5 \mathrm{ml})$ and $\mathrm{Hb}$ solutions at a concentration of 1-5 mM were filled into the syringe compartment (volume 100 $\mu l)$, each after thorough degassing of the suspensions by ultrasonification. After temperature equilibration, the hemoglobins were titrated in $3 \mu$ portions every 3 minutes into the lipidcontaining cell under constant stirring, and the measured heat of interaction after each 
injection measured by the ITC instrument was plotted versus time. The titration curves were repeated three times.

\section{$X$-ray diffraction}

X-ray diffraction measurements were performed at the European Molecular Biology Laboratory (EMBL) outstation at the Hamburg synchrotron radiation facility HASYLAB using the SAXS camera X33 [18]. Diffraction patterns in the range of the scattering vector 0.1 $<\mathrm{s}<1.0 \mathrm{~nm}^{-1}$ ( $\mathrm{s}=2 \sin \theta / \lambda, 2 \theta$ scattering angle and $\lambda$ the wavelength $=0.15 \mathrm{~nm}$ ) were recorded at $40{ }^{\circ} \mathrm{C}$ with exposure times of 1 min using an image plate detector with online readout (MAR345, MarResearch, Norderstedt/Germany). The s-axis was calibrated with Agbehenate which has a periodicity of $58.4 \mathrm{~nm}$. The diffraction patterns were evaluated as described previously [16] assigning the spacing ratios of the main scattering maxima to defined three-dimensional structures. The lamellar and cubic structures are most relevant here. They are characterized by the following features:

(1) Lamellar: The reflections are grouped in equidistant ratios, i.e., 1, 1/2, 1/3, 1/4, etc. of the lamellar repeat distance $d_{l}$

(2) Cubic: The different space groups of these non-lamellar three-dimensional structures differ in the ratio of their spacings. The relation between reciprocal spacing $s_{\mathrm{hkl}}=1 / \mathrm{d}_{\mathrm{hkl}}$ and lattice constant a is

$\mathrm{S}_{\mathrm{hkl}}=\left[\left(\mathrm{h}^{2}+\mathrm{k}^{2}+\mathrm{l}^{2}\right) / \mathrm{a}\right]^{1 / 2}$

(hkl = Miller indices of the corresponding set of plane).

\section{Laser backscattering analyses}

Size distribution measurements were performed by Non-Invasive Backscatter Detection (NIBS, Malvern Instruments) on a Zetasizer NANO S (Malvern Instruments, Herrenberg, Germany). The samples were measured for 3 minutes in a fixed laser position of $173^{\circ}$ relative 
to the incident laser beam. The measured intensities were correlated over time and analysed by a multiple exponential, non-negative least square fit to obtain relative intensities for the different particle sizes. The LPS samples were dispensed in $10 \mathrm{mM}$ TRIS buffer at $\mathrm{pH}=7$, temperature-cycled three times between $20^{\circ} \mathrm{C}$ and $60{ }^{\circ} \mathrm{C}$ and stored at room temperature. Hemoglobin samples were also dissolved in TRIS buffer $\mathrm{pH} 7$ and filtered with a $0.02 \mu \mathrm{m}$ filter device to get a solution of hemoglobin without protein aggregates. The LPS dispersions were then mixed $1: 1 \mathrm{v} / \mathrm{v}$ with the protein solution or with pure buffer.

\section{Results}

\section{Cytokine induction in mononuclear cells}

In previously published investigations, the increase in the LPS-induced biological responses caused by $\mathrm{Hb}$ was tested in serum-containing systems $[10,11]$. To exclude the influence of serum proteins, we have tested the ability of LPS R60 to induce the proinflammatory cytokine TNF $\alpha$ in human mononuclear cells under serum-free conditions in dependence on $\mathrm{Hb}$ concentration. At a concentration of $100 \mathrm{ng} / \mathrm{ml}$ LPS, the production of TNF $\alpha$ is more than 1.5 times higher in the presence of hemoglobin ([Hb]:[LPS] = 7:1 molar, Fig. 1). At a LPS concentration of $10 \mathrm{ng} / \mathrm{ml}$, still a significant increase in TNF $\alpha$ production is observed. Therefore, Hb causes an increase in LPS bioactivity independent of the presence of serum proteins.

\section{Binding stoichiometry}

By applying isothermal titration calorimetry (ITC), a 0.1 mM LPS R60 dispersion was titrated with a $1 \mathrm{mM}$ solution of hemoglobin (30 x $3 \mu \mathrm{l}$ every $5 \mathrm{~min}$ ) at different temperatures. As clearly demonstrated in Fig. 2 at $37^{\circ} \mathrm{C}$, an endothermic reaction takes place which remains more or less constant during the complete measurement, i.e., no binding saturation is 
observed. As can be seen in Fig. 2, a relatively constant isothermic reaction perpetuates without reduction of the enthalpy values. This is even valid at higher Hb concentrations up to $5 \mathrm{mM}$, and means that up to a concentration ratio of $[\mathrm{Hb}]:[\mathrm{LPS}]=1: 1$ molar the binding is not saturated. This observation was found to hold true also at other temperatures in the range 25 to $50{ }^{\circ} \mathrm{C}$. Therefore, the observed reactions could not be analysed by standard thermodynamical procedures due to this non-saturation process.

\section{Lipid A and LPS aggregate structure}

Synchrotron radiation X-ray diffraction was used to study the influence of hemoglobin on the three-dimensional aggregate structure of lipid A. The diffraction patterns observed at temperatures up to $60{ }^{\circ} \mathrm{C}$ of pure lipid A show - in accordance to previous results [19], a mixed unilamellar/non-lamellar aggregate structure (data not shown). The addition of hemoglobin induces a change in the supramolecular arrangement (Fig. 3a). The diffraction patterns of a [lipid A]:[Hb] = 160:1 molar preparation are indicative of a very complex aggregate structure. At $5{ }^{\circ} \mathrm{C}$, reflections at equidistant ratios $(7.11 \mathrm{~nm}, 3.52 \mathrm{~nm}$, and $2.37 \mathrm{~nm})$ indicate that part of the lipid A aggregates may adopt a multilamellar structure, with a periodicity of $7.11 \mathrm{~nm}$ which is much higher than that of pure lipid A (lying between 4.8 and $5.5 \mathrm{~nm}$ depending on water content and ion concentration [20]). At $60{ }^{\circ} \mathrm{C}$ (Fig. 3b), a diffraction pattern can be observed which should correspond to a non-lamellar, probably cubic phase. An assignment to a particular space group, however, is not possible.

Also, the influence of $\mathrm{Hb}$ on the aggregate structure of LPS Re was analysed. Pure LPS Re usually adopts mainly a unilamellar structure, sometimes also with some nonlamellar characteristics [21]. In the X-ray diffraction patterns of LPS Re in the presence of Hb ([LPS Re] : $[\mathrm{Hb}]=130: 1$ molar) broad reflexion maxima are observed, which are superimposed by weak reflexions (Fig. 4a). A closer look at, e.g., the measurement at $60{ }^{\circ} \mathrm{C}$ shows a very complex diffraction pattern (Fig. 4b). There is at least one defined cubic phase present. The 
reflections at 5.26, 4.08, 3.67, and $2.83 \mathrm{~nm}$ would fit to a periodicity at $9.1 \mathrm{~nm}$ (corresponding to the $1 / \sqrt{ } 3,1 / \sqrt{ } 5,1 / \sqrt{ } 6$, and $1 / \sqrt{ } 10$ reflections). Due to the fact that in no bicontinous cubic phase such group of reflections is observed, and that the other reflections are not so simply assignable, probably a superposition of at least two nonlamellar cubic phases takes place.

Finally, also the influence of $\mathrm{Hb}$ on the aggregate structure of LPS Ra was analysed. The latter adopts a unilamellar structure [22]. The X-ray diffraction pattern of a [LPS Ra]:[Hb] = 130:1 molar preparation exhibits a broad reflection maximum between $\mathrm{s}=0.1$ and $0.3 / \mathrm{nm}$ (data not shown). Additionally, at $5{ }^{\circ} \mathrm{C}$ various sharp reflections are seen (Fig. 5) which are indicative of a cubic phase not assignable to a particular space group.

Gel to liquid crystalline phase behaviour of lipid A acyl chains

Fourier-transform infrared spectroscopy (FTIR) was used to characterize the gel ( $\beta$ ) to liquid crystalline $(\alpha)$ phase transition of the acyl chains of the lipid A moiety in LPS. This method utilizes the fact that the peak position of the symmetric stretching vibration around $2850 \mathrm{~cm}^{-1}$ is a measure of lipid order, with a peak position around 2850 to $2851 \mathrm{~cm}^{-1}$ corresponding to the gel and 2852 to $2853 \mathrm{~cm}^{-1}$ to the liquid crystalline phase. Pure enterobacterial LPS preparations show phase transition temperatures around 30 to $35^{\circ} \mathrm{C}$ [16]. When adding Hb, for LPS Re as well as for LPS Ra only a very small change of the phase transition behaviour is observed (Fig. 6). For both LPS samples the presence of Hb leads to a small increase of the wavenumbers in the gel phase (fluidization) and a decrease in the liquid crystalline phase (rigidification). Such behaviour is known from the action of cholesterol in membrane lipids [23].

Size distribution of LPS aggregates 
As 'calibration standard' for the size distribution of LPS Re:protein mixtures, determined from non-invasive backscatter detection, that of a LPS:polymyxin B (PMB) complex was analysed, since PMB is known to cause a significant increase in the aggregate sizes of LPS [24, 25]. The result is shown in Fig. 7a. LPS alone has aggregate sizes between $40 \mathrm{~nm}$ and $1000 \mathrm{~nm}$, with a medium value around $320 \mathrm{~nm}$. These data shift to higher values of $60 \mathrm{~nm}$, $1100 \mathrm{~nm}$, and $400 \mathrm{~nm}$, respectively, in the presence of PMB.

The results for the LPS Re:Hb system are presented in Fig. 7b. Clearly, Hb causes an opposite effect to the size distribution of LPS as PMB, a decrease of aggregate sizes. The respective values are now $25 \mathrm{~nm}, 1000 \mathrm{~nm}$, and $220 \mathrm{~nm}$. This unequivocally corresponds to a disaggregation of LPS aggregates.

\section{Secondary structure of $\mathrm{Hb}$}

For the determination of the secondary structure of Hb, FTIR can be applied by analysing the amide I-vibration (predominantly $\mathrm{C}=\mathrm{O}$ stretching) in the wavenumber range 1700 to $1600 \mathrm{~cm}^{-}$

${ }^{1}$. In the case of an $\alpha$-helical structure, a strong band is found around 1650 to $1660 \mathrm{~cm}^{-1}$, whereas $\beta$-sheets vibrate around 1625 to $1640 \mathrm{~cm}^{-1}[17,26]$.

The wavenumber range of the amide I-band is presented in Fig. 8 for pure $\mathrm{Hb}$ (top) and in the presence of LPS ([LPS]:[Hb] 10:1 molar, bottom). There is a strong dominance of the band at $1653 \mathrm{~cm}^{-1}$ corresponding to a nearly completely $\alpha$-helical structure, in accordance with crystallographic data (Protein Data Bank, structure 1A06), and there is no change in the presence of LPS. This means that the LPS:Hb binding does not lead to detectable alterations of the secondary structure of $\mathrm{Hb}$. 


\section{Discussion}

Previously, the interaction of Hb with LPS has been described to lead to a considerable increase of the biological activities of LPS in the LAL test [7, 27], stimulation of endothelial cell tissue factor production [27], and an increase of endotoxin binding to endothelial cells and enhanced lethal toxicity $[28,29]$. Here, we have confirmed the ability of Hb to increase the cytokine-inducing activity of LPS in human mononuclear cells also in the absence of serum proteins (Fig. 1), by using highly purified preparations from fetal sheep $\mathrm{Hb}$ and from enterobacterial LPS Re and Ra, excluding any influence of contaminations on the results.

Preliminary monolayer data give some evidence that $\mathrm{Hb}$ interacts with patches from LPS aggregates, which leads to a considerable decrease in molecular area (data not shown). In contrast, for all other investigated LPS-binding proteins so far, rather than a decrease an increase in molecular area of LPS due to protein binding is observed [30]. Strong evidence for the hypothesis that LPS does not form high-affinity complexes with hemoglobin in contrast to the binding with other proteins are the data of the calorimetric isothermic titrations (Fig. 2). For LPS-protein or -peptide interactions investigated at physiological temperature of $37{ }^{\circ} \mathrm{C}$, the binding enthalpy was found to be an exothermic process with a clear saturation according to their binding stoichiometry [15, 25]. For example, for the binding of LPS to recombinant human serum albumin (HSA), a protein with a nearly identical molecular weight $(64 \mathrm{kD})$ as $\mathrm{Hb}$, from ITC measurements binding saturation was found to take place at a $[\mathrm{HSA}]:[\mathrm{LPS}]=$ 0.08 molar ratio [15]. The endothermic reaction observed here with no saturation even at a very high [Hb]:[LPS] 1:1 molar ratio is indicative for a completely different process of interaction. This process would be fully compatible with a dissolution of smaller LPS units from the large aggregates, and is confirmed by the observed change in the size distribution of LPS Re (Fig. 7b) leading to a significant reduction in size. Furthermore, accompanied by these observations is the reorientation of the aggregate structure of lipid A, LPS Re, and LPS Ra (Fig. 3-5). The binding of Hb to LPS induces very complex inverted aggregate structures 
with cubic symmetry in particular at higher temperature, for LPS Ra even already at $5{ }^{\circ} \mathrm{C}$. The reduction of the aggregate size is probably connected with more accessible binding epitopes for serum and membrane proteins important in cell signalling such as LBP, MD-2, and CD14, because the cubic structures have large water-filled channels pervading the network, for which as model the bicontinous cubic structures $Q^{224}$, (symmetry Pn3m, [31]) may serve. These conclusions are supported by a previous electron microscopic demonstration that $\mathrm{Hb}$ induced disaggregation of LPS, with production of smaller particles of LPS [12] (it should be noted that with typical electron microscopic investigations a differentiation of the aggregate structures is not possible).

From our data it can be furthermore concluded that the hydrophobic lipid A moiety of endotoxins interacts with hydrophobic regions of $\mathrm{Hb}$, which would be consistent with a previous consideration [32]. This can be deduced from the cholesterol-like effect of the gel to liquid crystalline phase transition (Fig. 6) which would imply that hydrophilic and hydrophobic moieties of $\mathrm{Hb}$ as well as LPS are aligned parallel. However, the phase transition data also suggest that $\mathrm{Hb}$ binding does not disturb the packing density or space requirement of the hydrophobic moiety strongly, since no shift of the phase transition temperature takes place, and the mobility of the LPS acyl chains in each phase is only slightly changed.

Presently we do not understand every aspect of the enhancement of the LPS-induced cytokine production caused by Hb. According to the arguments mentioned above, however, it can be concluded that (i) the binding to LPS of proteins important for cell activation such as LBP and CD14 is facilitated, (ii) the disaggregation leads to a better accessibility of bioreactive LPS epitopes and (iii) the binding energy of the LPS assembly is lowered. Further experiments are required to determine whether additional factors are involved in the Hb-induced enhancement of endotoxin bioactivity. 


\section{Acknowledgements:}

The authors gratefully acknowledge the financial support of the 'Clinique La Prairie', Montreux, Switzerland. We thank also G. von Busse and K. Stephan for support in various infrared, microcalorimetric, and biological experiments. We thank the Malvern company for the possibility to perform some measurements in their application laboratory in Herrenberg (Germany).

\section{References}

[1] Rietschel E.Th.; Kirikae T.; Schade F.U.; Mamat U.; Schmidt G.; Loppnow H.; Ulmer A.J.; Zähringer U.; Seydel U.; Di Padova F.; Schreier M.; Brade H. FASEB J., 1994, 8,217

[2] Zähringer U.; Lindner B.; Rietschel E.T. Adv. Carbohydr. Chem. Biochem., 1994, 50, 211

[3] Brandenburg K.; Jürgens G.; Müller M.; Fukuoka S.; Koch M.H.J. Biol. Chem., 2001, 382, 1215

[4] Brandenburg K.; Jürgens G.; Andrä J.; Lindner B.; Koch M.H.J.; Blume A.; Garidel P. Eur. J. Biochem., 2002, 269, 5972

[5] Bensinger T.A.; Gillette P.N. Arch. Intern. Med. 1974, 133, 624

[6] Reiter C.D.; Wang X.; Tanus-Santos J.E.; Hogg N.; Cannon R.O.; Schechter A.N.; Gladwin M.T. Nat. Med. 2002, 8, 1383

[7] Roth R.I.; Kaca W.; Levin J. Prog. Clin. Biol. Res., 1994, 388, 161

[8] Roth R.I. and Kaca W. Biomater. Artif. Cells Immobilization Biotechnol., 1994, 22, 387

[9] Kaca W.; Roth R.I.; Levin J. J. Biol. Chem., 1994, 269, 25078

[10] Jürgens G.; Müller M.; Koch M.H.J.; Brandenburg K. Eur. J. Biochem., 2001, 268, 4233

[11] Brandenburg K.; Garidel P.; Andrä J.; Jürgens G.; Müller M.; Blume A.; Koch M.H.J.; Levin J. J. Biol. Chem., 2003, 278, 47660

[12] Roth R.I.; Wong J.S.; Hamilton .R.L. J. Endotoxin Res., 2006, 3, 361

[13] Galanos C.; Lüderitz O.; Westphal O. Eur. J. Biochem., 1969, 9, 245 
[14] Gorczynski,R.M.; Alexander,C.; Bessler,W.; Fournier,K.; Hoffmann,P.; Mach,J.P.; Manuel,J.; Ramakrishna,V.; Rietschel,E.T.; Song,L.; Waelli,T.; Westphal,O.; Zähringer,U. Internat. Immunopharmacol. 2004, 4, 1859

[15] Jürgens G.; Müller M.; Garidel P.; Koch M.H.J.; Nakakubo H.; Blume A.; Brandenburg K. J. Endotoxin Res., 2002, 8, 115

[16] Brandenburg K.; Funari S.S.; Koch M.H.J.; Seydel U. J. Struct. Biol., 1999, 128, 175

[17] Arrondo J.L. and Goni F.M. Prog. Biophys. Molec. Biol., 1999, 72, 367

[18] Koch M.H.J. and Bordas J. Nucl. Instr. Meth., 1983, 208, 461

[19] Brandenburg K.; Richter W.; Koch M.H.J.; Meyer H.W.; Seydel U. Chem. Phys. Lipids, 1998, 91, 53

[20] Brandenburg K.; Koch M.H.J.; Seydel U. J. Struct. Biol., 1990, 105, 11

[21] Brandenburg K.; Koch M.H.J.; Seydel U. J. Struct. Biol., 1992, 108, 93

[22] Seydel U.; Koch M.H.J.; Brandenburg K. J. Struct. Biol., 1993, 110, 232

[23] Urbina J.A.; Pekerar S.; Le H.B.; Patterson J.; Montez B.; Oldfield E. Biochim. Biophys. Acta, 1995, 1238, 163

[24] Thomas C.J. and Surolia A. FEBS Lett., 1999, 445, 420

[25] Brandenburg K.; Moriyon I.; Arraiza M.D.; Lehwark-Yvetot G.; Koch M.H.J.; Seydel U. Thermochim. Acta, 2002, 382, 189

[26] Goormaghtigh E.; Cabiaux V.; Ruysschaert J.-M. Eur. J. Biochem., 1990, 193, 409

[27] Kaca W.; Roth R.I.; Ziolkowski A.; Levin J. J. Endotoxin Res., 1994, 1, 243

[28] Roth R.I. Thromb. Haemostasis, 1996, 76, 258

[29] Su D.H.; Roth R.I.; Yoshida M.; Levin J. Infect. Immun., 1997, 65, 1258

[30] Gutsmann T.; Fix M.; Larrick J.W.; Wiese A. J. Membrane Biol., 2000, 176, 223

[31] Mariani P.; Luzzati V.; Delacroix H. J. Mol. Biol., 1993, 204, 165

[32] Kaca W.; Roth R.I.; Vandegriff K.D.; Chen G.C.; Kuypers F.A.; Winslow R.M.; Levin J. Biochemistry, 1995, 34, 11176 
Fig. 1: LPS Ra-induced production of TNF $\alpha$ by human mononuclear cells under serum-free conditions in the absence and presence of $\mathrm{Hb}$ ([Hb]:[LPS] 100:1 weight $\% \approx 7: 1$ molar). LPS Ra was from strain S. minnesota R60.

Fig. 2: Isothermal calorimetric titration of $0.1 \mathrm{mM}$ LPS Ra with $1 \mathrm{mM} \mathrm{Hb}$, adding every 5 min. $3 \mu$ for 30 times. (a) Feedback power against time. The peaks directed upward are characteristic for an endothermic process. (b) Enthalpy change $\Delta \mathrm{H}$ against [Hb]:[LPS] molar ratio. There is only a marginal decrease in $\Delta \mathrm{H}$ indicative for a non-saturated process.

Fig. 3: Synchrotron radiation small-angle X-ray diffraction patterns of lipid A at (a) 5 to 60 ${ }^{\circ} \mathrm{C}$ and (b) $60^{\circ} \mathrm{C}$ and $95 \%$ water content. Presented is the logarithm of the scattering intensity against scattering vector $\mathrm{s}=1 / \mathrm{d}=2 \sin \theta / \lambda$. Lipid A was isolated from LPS of $S$. minnesota R595.

Fig. 4: Synchrotron radiation small-angle X-ray diffraction patterns of LPS Re at (a) 5 to 60 ${ }^{\circ} \mathrm{C}$ and (b) $60^{\circ} \mathrm{C}$ and $95 \%$ water content. Presented is the logarithm of the scattering intensity against scattering vector $\mathrm{s}=1 / \mathrm{d}=2 \sin \theta / \lambda$.

Fig. 5: Synchrotron radiation small-angle X-ray diffraction patterns of LPS Ra at $5{ }^{\circ} \mathrm{C}$ and 95 \% water content. Presented is the logarithm of the scattering intensity against scattering vector $\mathrm{s}=1 / \mathrm{d}=2 \sin \theta / \lambda$.

Fig. 6: Gel to liquid crystalline phase transition of the hydrocarbon chains of $10 \mathrm{mM}$ preparations from LPS Re (a) and LPS Ra (b) in the absence (black squares) and presence 
(hollow squares) of Hb. Presented is the peak position of the symmetric stretching vibrational band $v_{\mathrm{s}}\left(\mathrm{CH}_{2}\right)$ versus temperature with FTIR. The gel phase is around 2850 to $2850.5 \mathrm{~cm}^{-1}$, the liquid crystalline phase in the range 28952.5 to $2853.0 \mathrm{~cm}^{-1}$.

Fig. 7: Size distribution with Laser light backscattering of (a) LPS Re $(0.01 \mathrm{mM})$ in the absence (top) and presence (bottom) of polymyxin B (0.001 mM), (b) LPS Re (0.01 mM) in the absence (top) and presence (bottom) of filtered $\mathrm{Hb}$ (concentration undetermined).

Fig. 8: Amide I vibrational band in the wavenumber range 1700 to $1600 \mathrm{~cm}^{-1}$ for $0.1 \mathrm{mM} \mathrm{Hb}$ (top) and in the presence of LPS Re, [LPS]:[Hb] = 10:1 molar (bottom). The band position is typical for the occurrence of an $\alpha$-helical structure. 


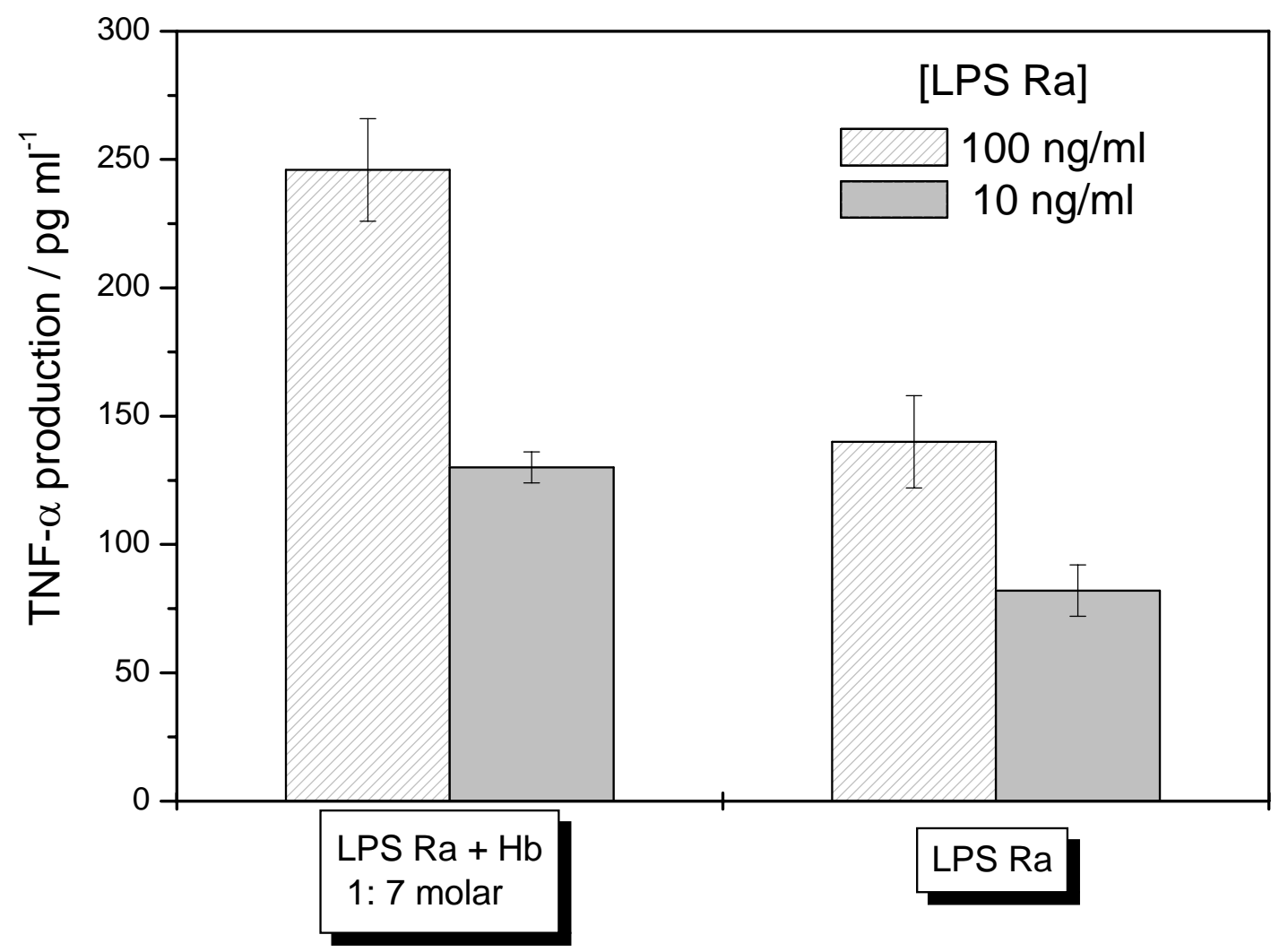

Fig. 1 


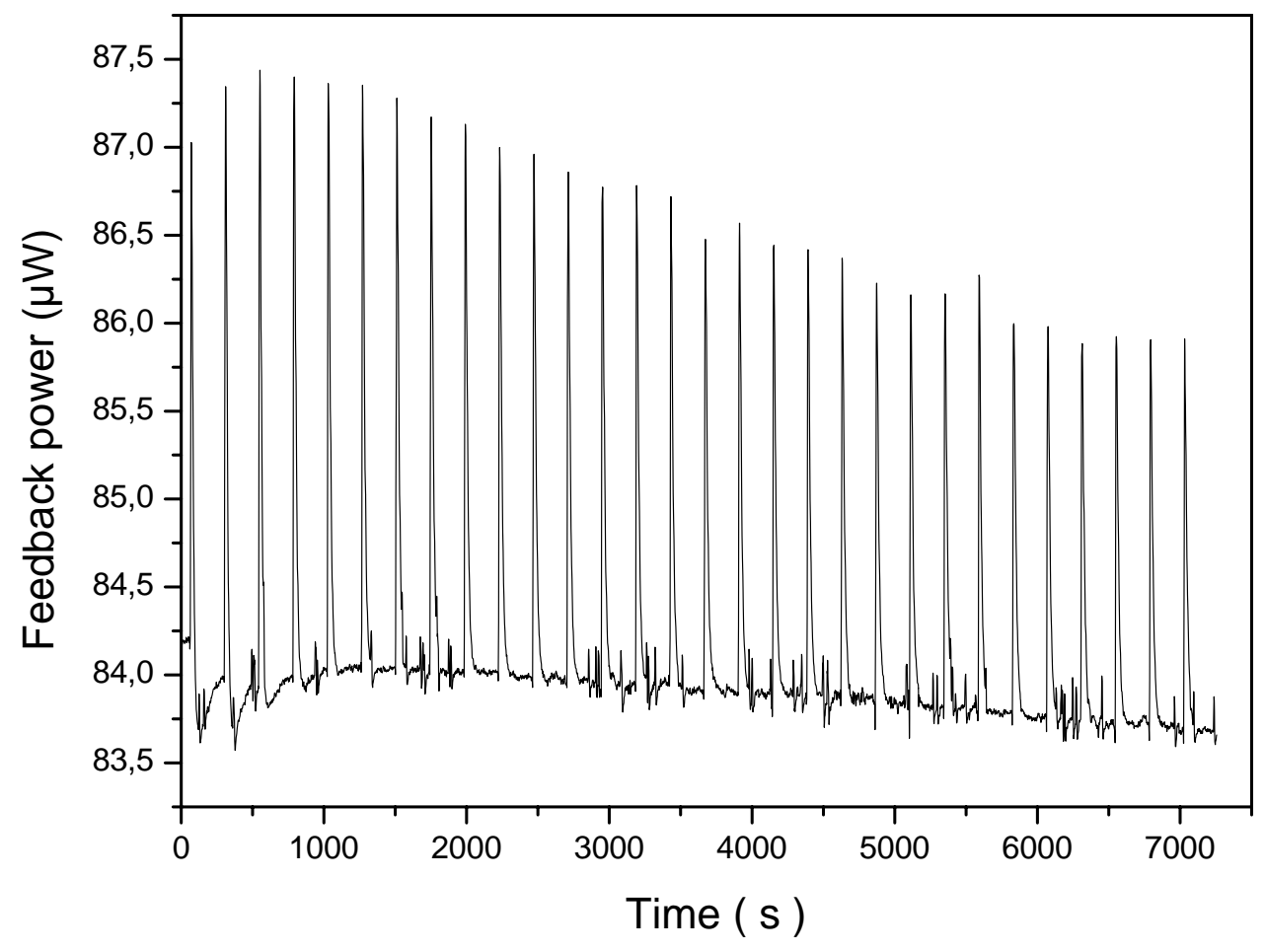

Fig. 2a 


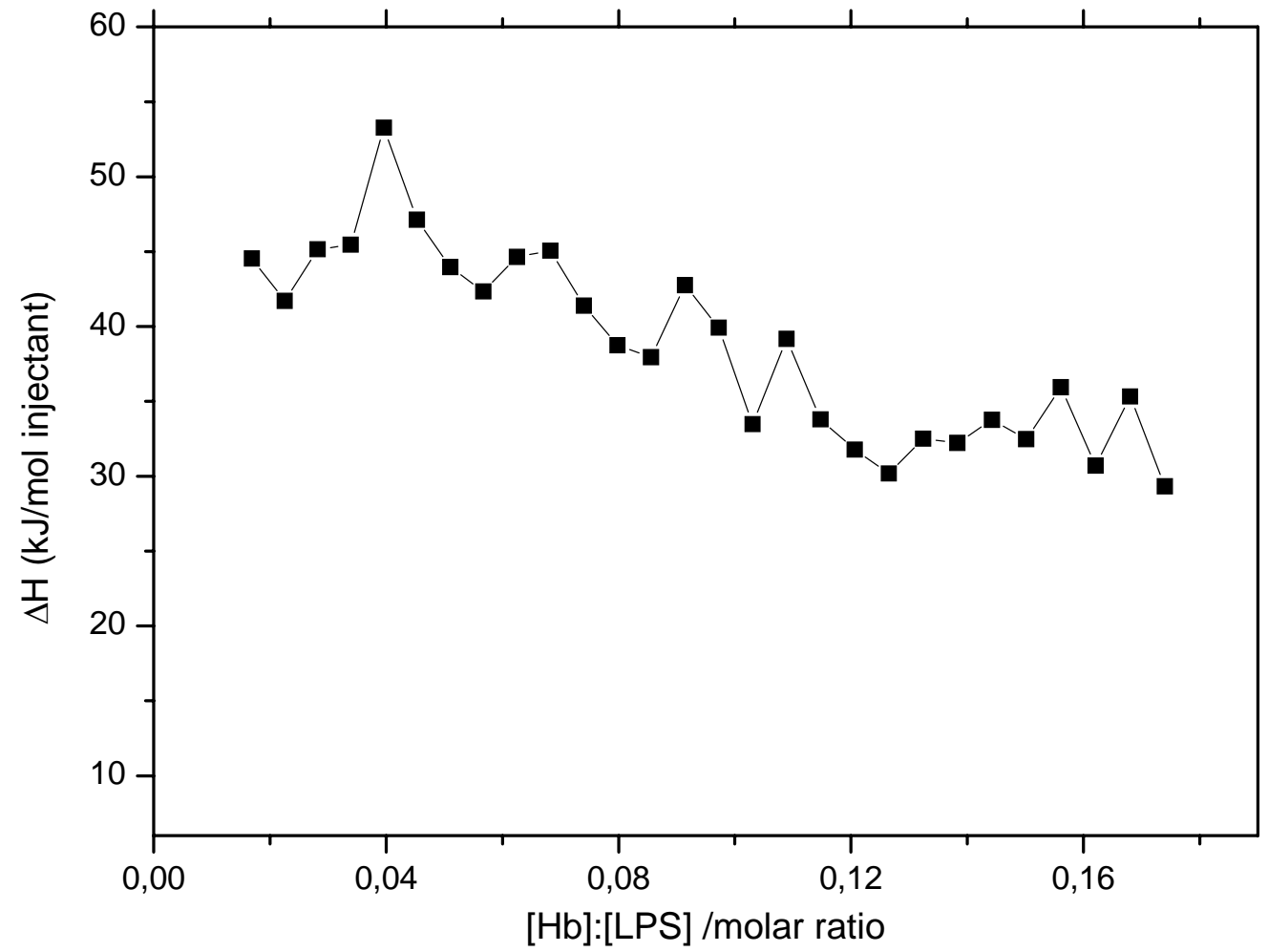

Fig. 2b 


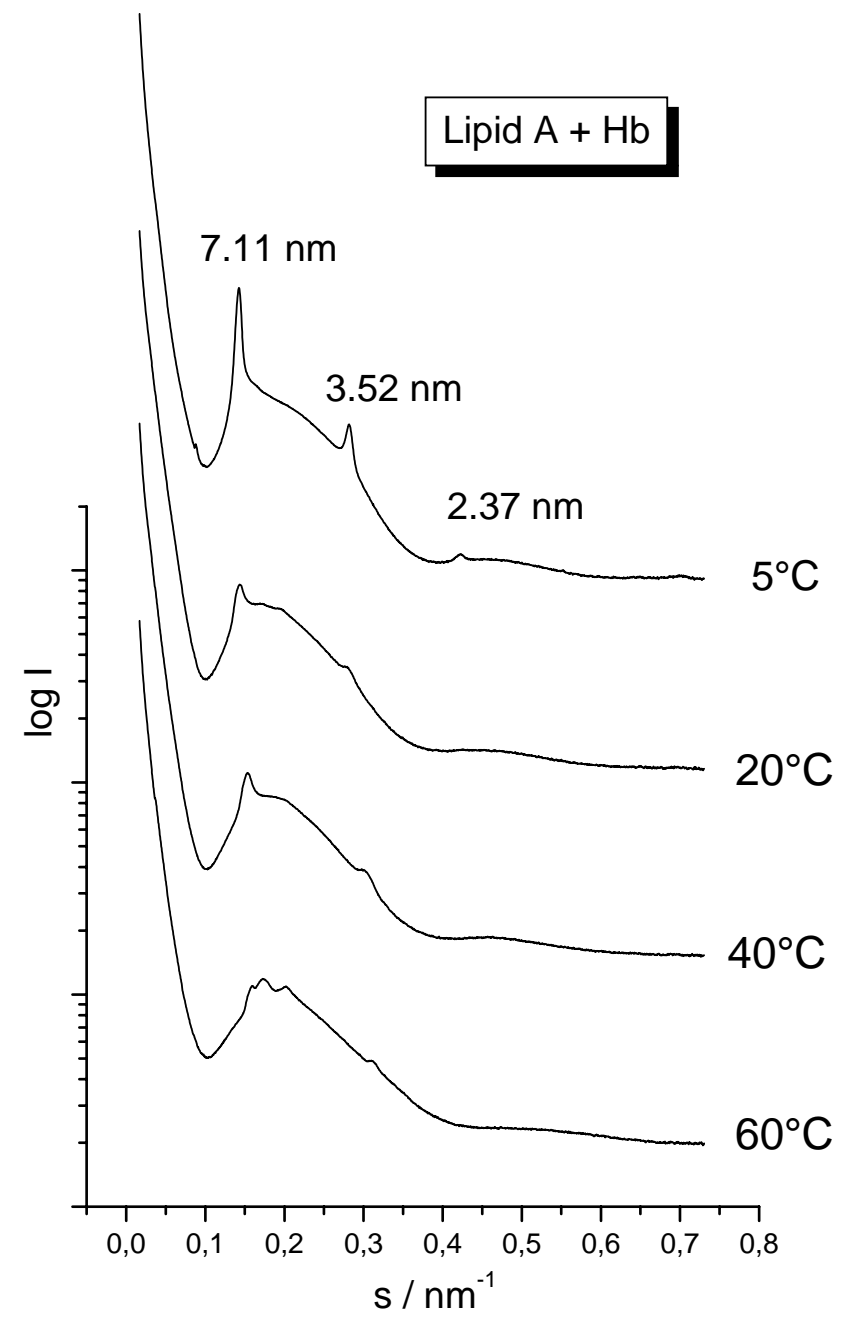

Fig. 3a 


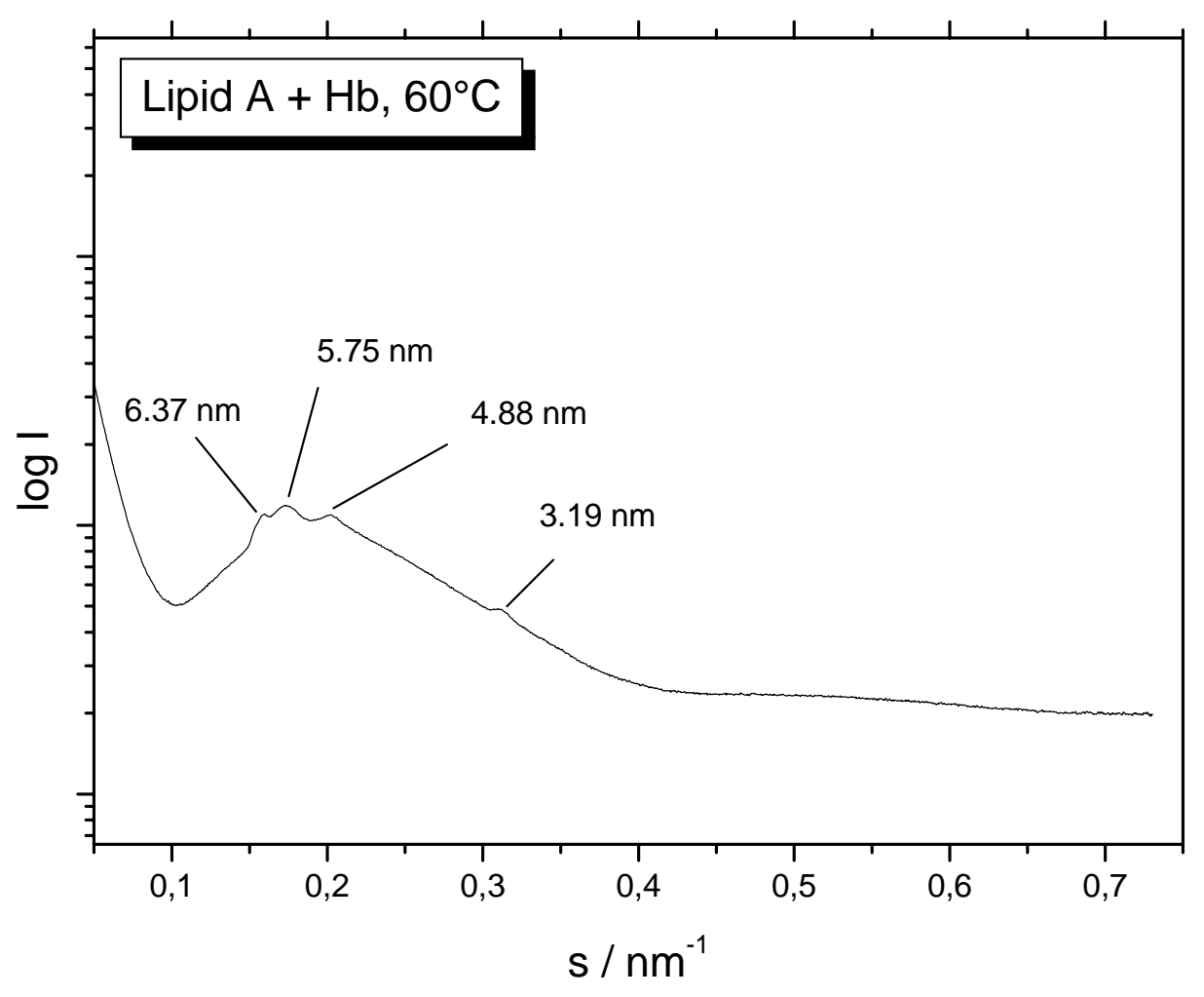

Fig. 3b 


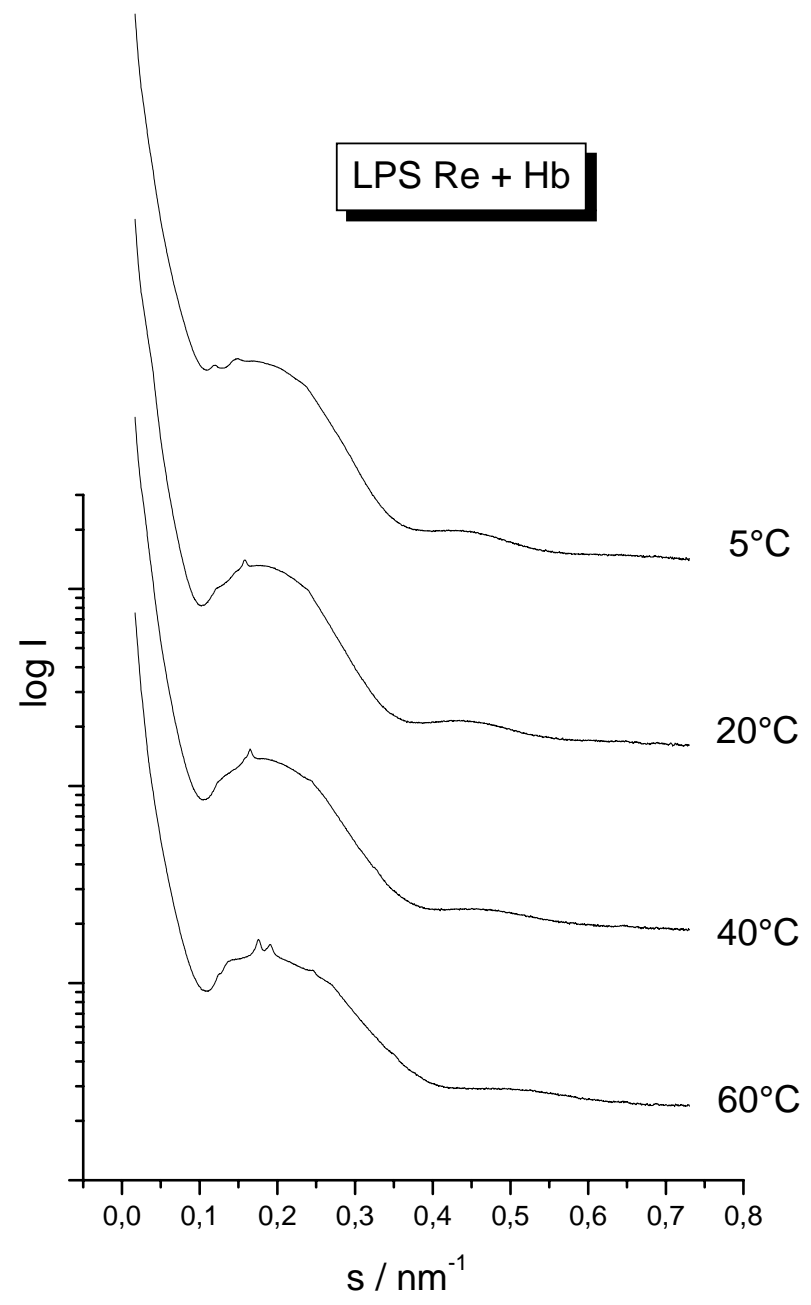

Fig. 4a 


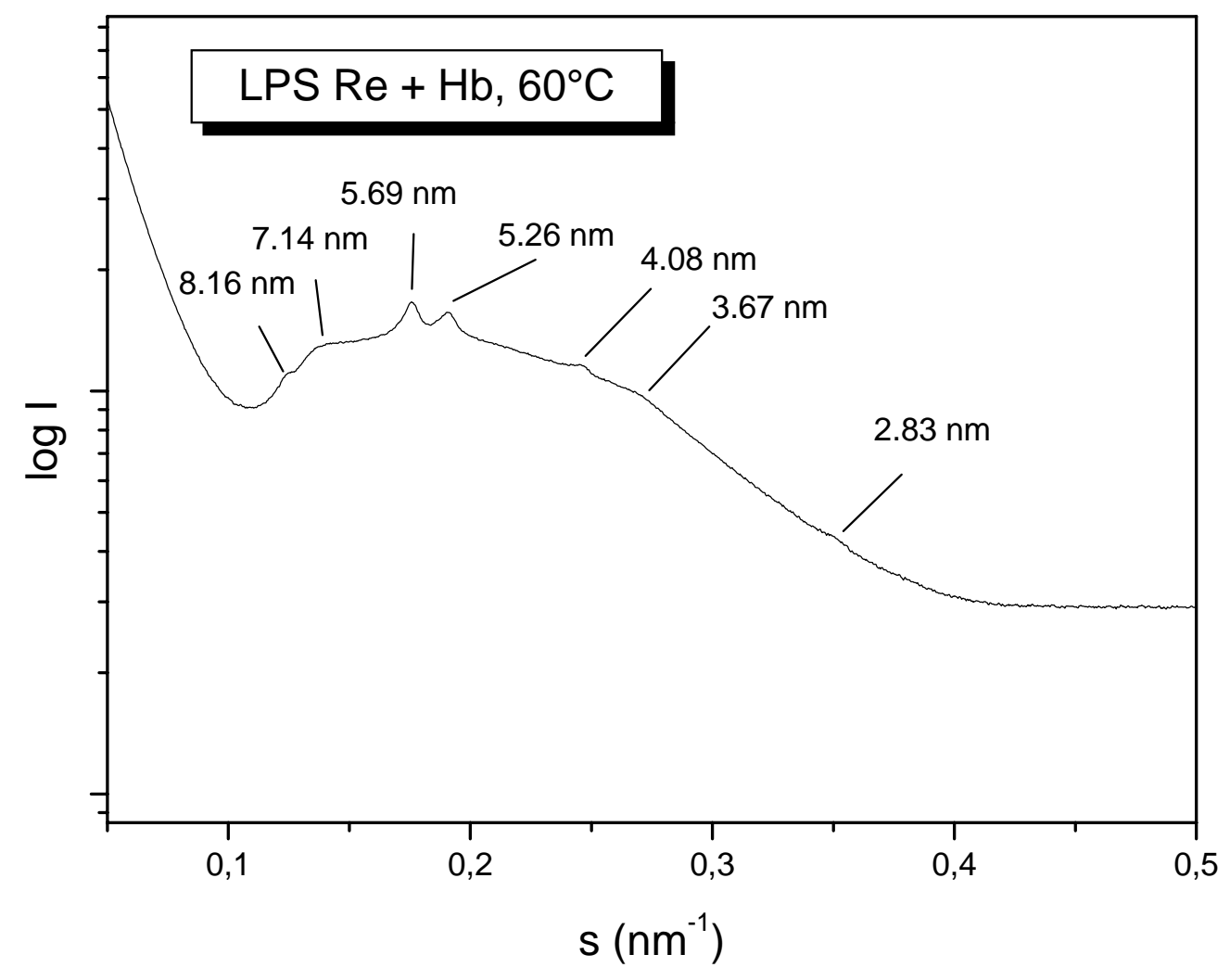

Fig. 4b 


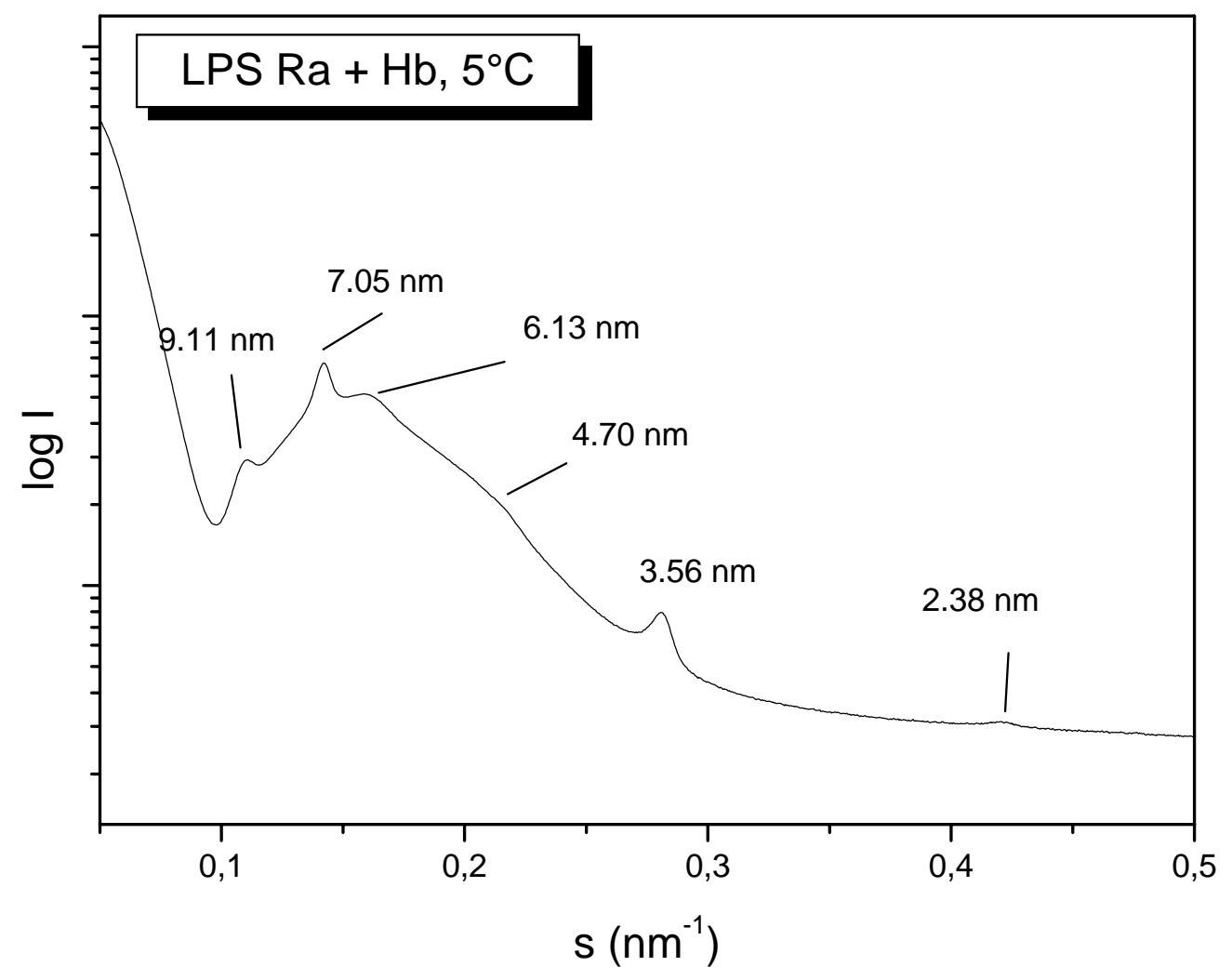

Fig. 5 


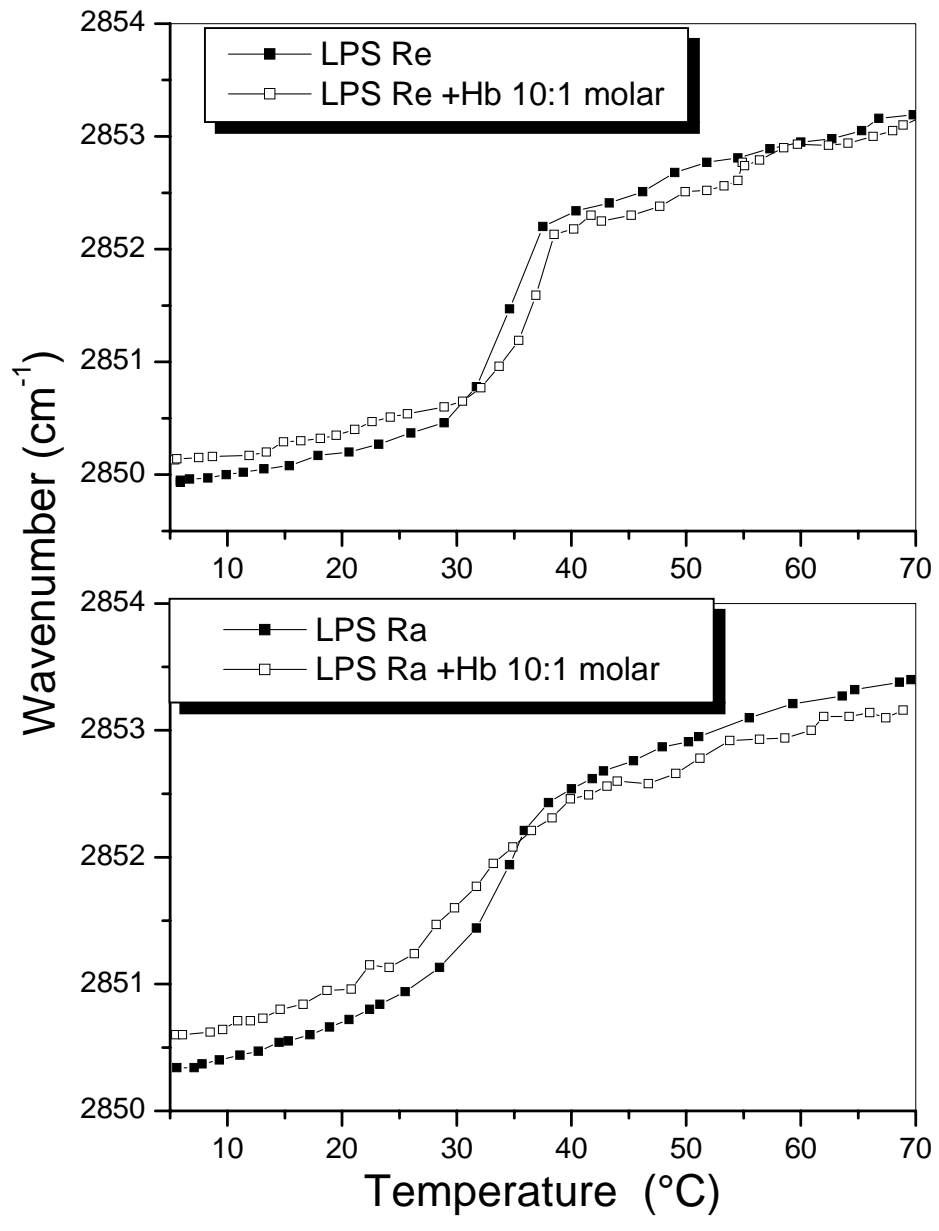

Fig. 6 

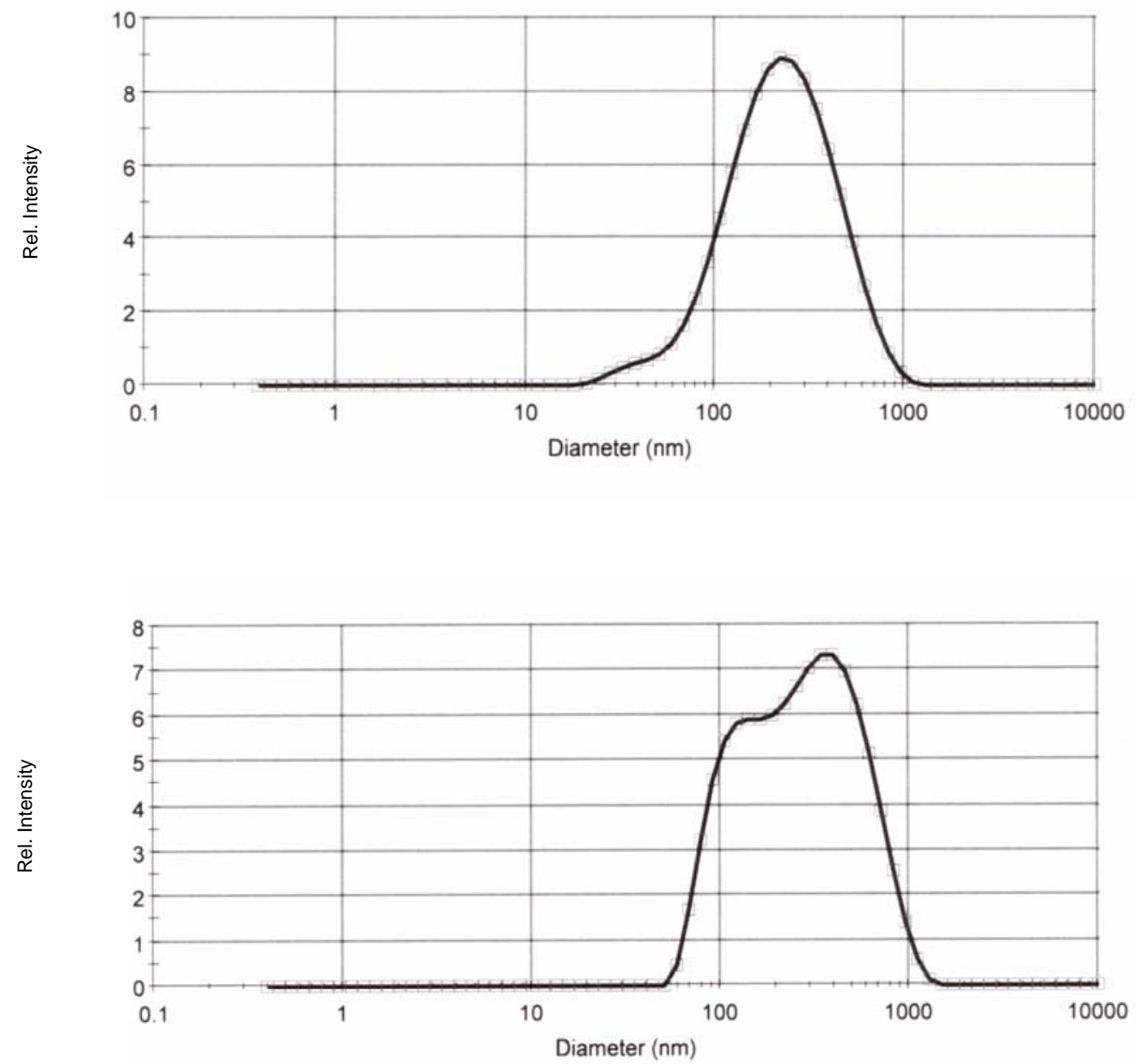

Fig.7a 

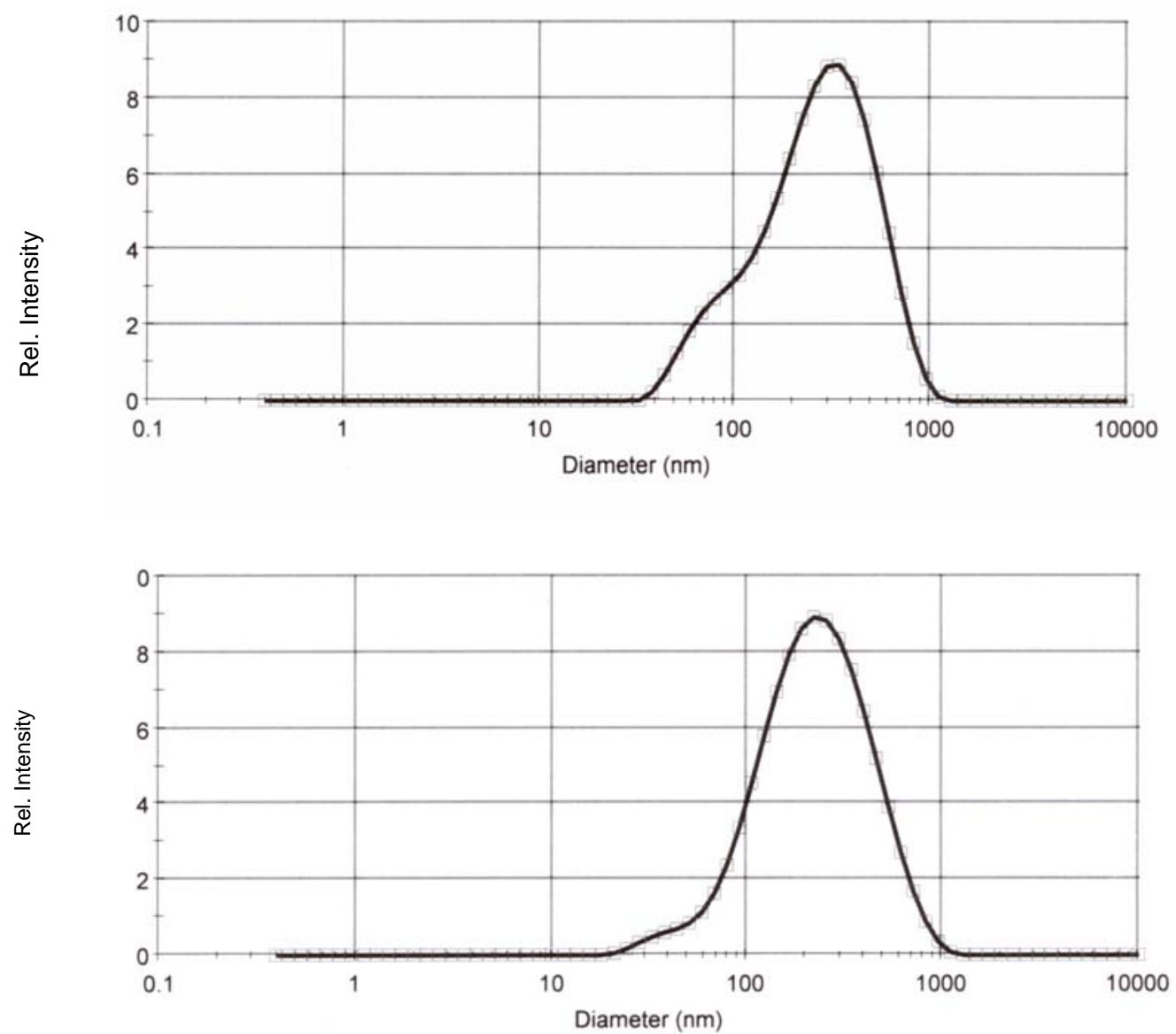

Fig. 7b 

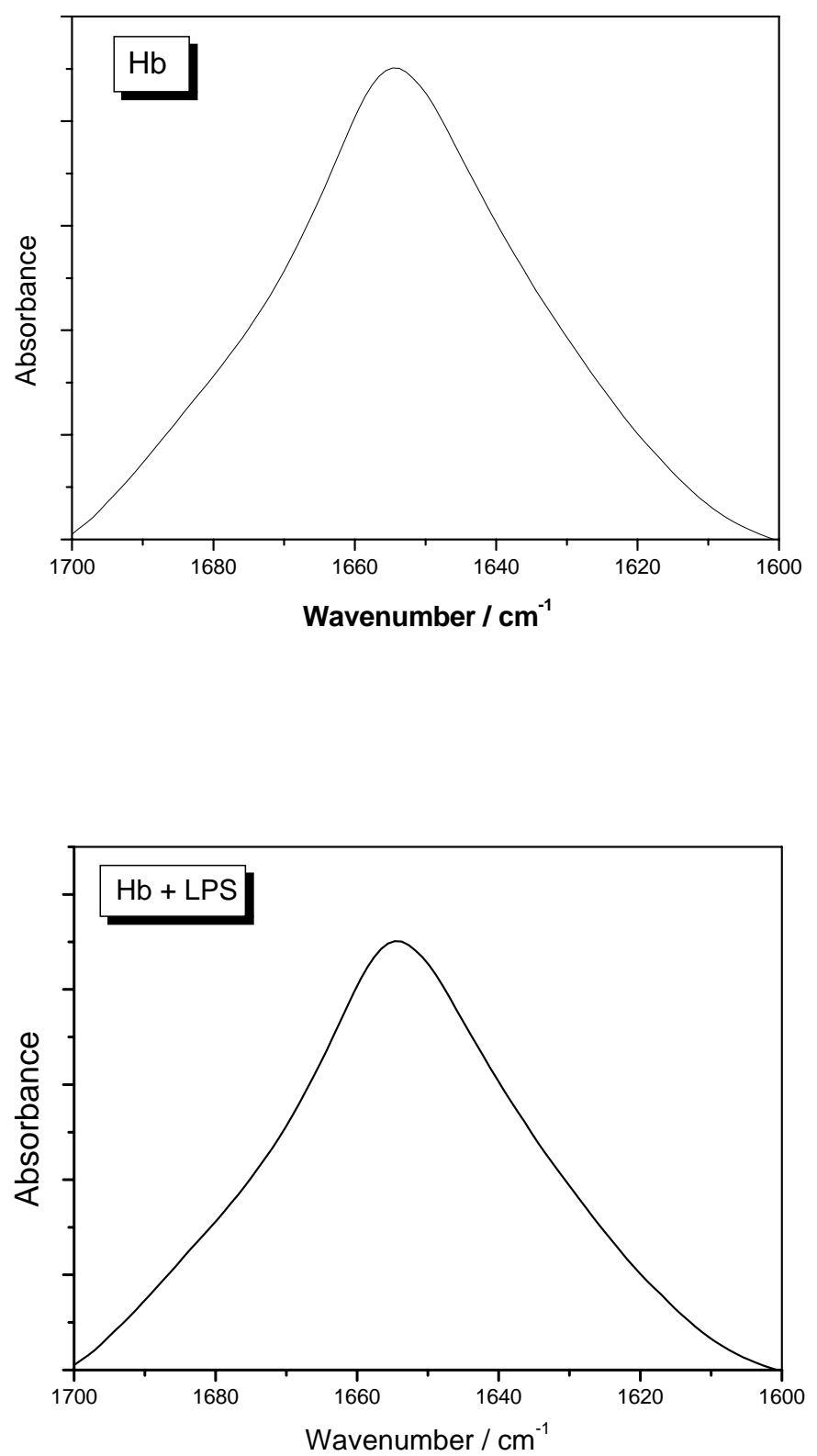

Fig. 8 